\title{
Cannabidiol Attenuates Cisplatin-Induced Nephrotoxicity by Decreasing Oxidative/Nitrosative Stress, Inflammation, and Cell Death
}

\author{
Hao Pan, Partha Mukhopadhyay, Mohanraj Rajesh, Vivek Patel, Bani Mukhopadhyay, \\ Bin Gao, György Haskó, and Pál Pacher \\ Department of Urology, The First Affiliated Hospital, College of Medicine, Zhejiang University, Hangzhou, Zhejiang, China \\ (H.P.); Sections on Liver Biology and Oxidative Stress Tissue Injury, Laboratory of Physiologic Studies, National Institute on \\ Alcohol Abuse and Alcoholism, National Institutes of Health, Bethesda, Maryland (H.P., P.M., M.R., V.P., B.M., B.G., P.P.); and \\ Department of Surgery, University of Medicine and Dentistry of New Jersey-New Jersey Medical School, Newark, New Jersey \\ (G.H.)
}

Received October 8, 2008; accepted December 11, 2008

\begin{abstract}
The platinum compound cisplatin is one of the most potent chemotherapy agents available to treat various malignancies. Nephrotoxicity is a common complication of cisplatin chemotherapy, which involves increased oxidative and nitrosative stress, limiting its clinical use. In this study, we have investigated the effects of a nonpsychoactive cannabinoid cannabidiol, which was reported to exert antioxidant effects and has recently been approved for the treatment of inflammation, pain, and spasticity associated with multiple sclerosis in patients in a mouse model of cisplatin-induced nephropathy. Cisplatin induced increased expression of superoxide-generating enzymes RENOX (NOX4) and NOX1, enhanced reactive oxygen species generation, inducible nitric-oxide synthase expression,
\end{abstract}

nitrotyrosine formation, apoptosis (caspase-3/7 activity, DNA fragmentation, and terminal deoxynucleotidyl transferase dUTP nick-end labeling staining), poly(ADP-ribose) polymerase activity, and inflammation (tumor necrosis factor- $\alpha$ and interleukin-1 $\beta$ ) in the kidneys of mice, associated with marked histopathological damage and impaired renal function (elevated serum blood urea nitrogen and creatinine levels) $72 \mathrm{~h}$ after the administration of the drug. Treatment of mice with cannabidiol markedly attenuated the cisplatin-induced oxidative/nitrosative stress, inflammation, and cell death in the kidney, and it improved renal function. Thus, our results suggest that cannabidiol may represent a promising new protective strategy against cisplatin-induced nephrotoxicity.
Cisplatin, a platinum compound, is one of the most potent chemotherapy agents available to treat a variety of malignancies, including ovarian, lung, head, and neck cancers, as well as testicular and bladder tumors (Ries and Klastersky, 1986; Wang and Lippard, 2005). Unfortunately, cisplatin induces cumulative and dose-dependent nephrotoxicity, which restricts the use of high doses to maximize the therapeutic efficacy. Approximately, one third of patients experience renal dysfunction after treatment with cisplatin (Ries and Klastersky, 1986). Cisplatin is taken up by renal tubular

This study was supported by the Intramural Research Program of National Institutes of Health National Institute on Alcohol Abuse and Alcoholism.

H.P. and P.M. contributed equally to this work.

Article, publication date, and citation information can be found at http://jpet.aspetjournals.org.

doi:10.1124/jpet.108.147181 cells after administration, with proximal tubular cells of the inner cortex and outer medulla absorbing the highest concentrations of the drug. As a result, these segments are the major sites of cisplatin-induced renal injury, and the loss of tubular cells by necrosis and apoptosis is followed by infiltration of inflammatory cells. The cisplatin-induced nephrotoxicity is a complex process (Pabla and Dong, 2008), which has been reported to involve DNA damage, caspase activation, mitochondrial dysfunction (Sugiyama et al., 1989), formation of reactive oxygen (Matsushima et al., 1998; Davis et al., 2001) and nitrogen species (Chirino et al., 2004, 2008), poly(ADP-ribose) polymerase (PARP) overactivation (Racz et al., 2002), and inflammation (Yamate et al., 2002; Faubel et al., 2007). Multiple lines of recent evidence suggest an important role for inflammatory mechanisms mediating the pathogenesis of cisplatin-induced nephrotoxicity through the

ABBREVIATIONS: PARP, poly(ADP-ribose) polymerase; TNF, tumor necrosis factor; IL, interleukin; CB, cannabinoid; CBD, cannabidiol; BUN, blood urea nitrogen; iNOS, inducible nitric-oxide synthase; PAS, periodic acid-Schiff; ROS, reactive oxygen species; MDA, malondialdehyde; TUNEL, terminal deoxynucleotidyl transferase dUTP nick-end labeling staining; ELISA, enzyme-linked immunosorbent assay; PCR, polymerase chain reaction; CP, cisplatin; NT, 3-nitrotyrosine. 
recruitment of inflammatory cells, such as macrophages and leukocytes, that contribute to the cisplatin-induced damage (Ramesh and Reeves, 2002; Yamate et al., 2002; Faubel et al., 2007; Zhang et al., 2007). Furthermore, cisplatin induces increased renal expression of a variety of inflammatory chemokines and cytokines, such as tumor necrosis factor (TNF) $-\alpha$ and interleukin (IL)-1 $\beta$ (Ramesh and Reeves, 2002; Zhang et al., 2007). Cisplatin-induced kidney injury largely depends on TNF- $\alpha$, because TNF- $\alpha$-deficient mice and TNF- $\alpha$ antibody-treated wild-type mice display resistance to cisplatin-induced kidney damage as reported previously (Ramesh and Reeves, 2002; Zhang et al., 2007).

Cannabinoids [components of the Cannabis sativa (marijuana) plant] are known anti-inflammatory, immunomodulatory, and analgesic agents, which exert these effects through the activation of $\mathrm{CB}_{1}$ and $\mathrm{CB}_{2}$ cannabinoid receptors located in the central nervous system and immune cells (Pacher et al., 2006). However, the limitation of the therapeutic use of the major cannabinoid $\delta$-9-tetrahydrocannabinol is the development of psychoactive effects mediated through $\mathrm{CB}_{1}$ receptor in the central nervous system (Pacher et al., 2006). On the contrary, cannabidiol (CBD), one of the most abundant cannabinoids of $C$. sativa is devoid of psychoactive properties because of a low affinity for the $\mathrm{CB}_{1}$ and $\mathrm{CB}_{2}$ receptors (Pacher et al., 2006). CBD is well tolerated without side effects when chronically administered to humans and has been reported to exert antioxidant, anti-inflammatory, and immunomodulatory effects (Cunha et al., 1980; Consroe et al., 1991; Mechoulam et al., 2007).

Here, we have studied the effects of CBD on cisplatininduced oxidative/nitrosative stress, inflammation, and tissue injury in the kidney using a well established mouse model of cisplatin-induced nephropathy. Our results may have important relevance for the prevention of the cisplatininduced nephrotoxicity.

\section{Materials and Methods}

Animals and Drug Treatment. All animal experiments conformed to National Institutes of Health guidelines and were approved by the Institutional Animal Care and Use Committee of the National Institute on Alcohol Abuse and Alcoholism (Bethesda, MD). Six to 8-week-old male C57BL/6J mice were obtained from The Jackson Laboratory (Bar Harbor, ME). All animals were kept in a temperature-controlled environment with a 12-h light/dark cycle and were allowed free access to food and water at all times. Animals were cared for in accordance with National Institutes of Health guidelines.

Mice were sacrificed $72 \mathrm{~h}$ after a single injection of cisplatin [cis-diammineplatinum(II) dichloride, $20 \mathrm{mg} / \mathrm{kg}$ i.p.; Sigma-Aldrich, St. Louis, MO] administration. Cannabidiol was used at 2.5 to 10 $\mathrm{mg} / \mathrm{kg}$ i.p. everyday, starting $1.5 \mathrm{~h}$ before the cisplatin exposure to establish the dose-response relationship (Fig. 1), and at $10 \mathrm{mg} / \mathrm{kg} /$ day in experiments aiming to characterize its detailed mechanism of action (Figs. 2-7). CBD was isolated from hashish as described previously (Gaoni and Mechoulam, 1971). Sources of all the other reagents used in the experiments are mentioned in the text wherever appropriate.

Renal Function Monitoring. On the day of the sacrifice, blood was collected immediately, and serum levels of creatinine and blood urea nitrogen (BUN) were measured using a clinical chemistry analyzer system and kits (Prochem-V; Drew Scientific, Dallas, TX).

Western Blot Analysis. Anti-iNOS and anti- $\beta$-actin antibodies were obtained from Cell Signaling Technology Inc. (Danvers, MA). The kidney protein samples were mixed in Laemmli loading buffer, boiled for $10 \mathrm{~min}$, and then subjected to SDS-polyacrylamide gel electrophoresis. After electrophoresis, proteins were transferred onto nitrocellulose membranes and blotted against primary antibody (1:1000 dilution) for $16 \mathrm{~h}$. Membranes were washed with phosphatebuffered saline/Tween 20 and incubated with a secondary antibody (1:1000 dilution) for $2 \mathrm{~h}$. Protein bands were visualized by chemiluminescence reaction using SuperSignal West Pico Substrate (Thermo Fisher Scientific, Waltham, MA).

Histological Examination. After fixation of the kidneys with $10 \%$ formalin, renal tissues were sectioned and stained with periodic acid-Schiff (PAS) reagents for histological examination. Tubular damage in PAS-stained sections was examined under the microscope (200× magnification) and scored based on the percentage of cortical tubules showing epithelial necrosis: 0 , normal; $1,<10 \% ; 2,10$ to $25 \%$; 3,26 to $75 \%$; and $4,>75 \%$. Tubular necrosis was defined as the loss of the proximal tubular brush border, blebbing of apical membranes, tubular epithelial cell detachment from the basement membrane, or intraluminal aggregation of cells and proteins. The morphometric examination was performed in a blinded manner by two independent investigators.

ROS Production. Malondialdehyde (MDA) is one of the end products of lipid peroxidation and an indicator of ROS production. MDA was quantified in tissues as described previously, with some minor modifications (Pacher et al., 2003). In brief, tissues were homogenized $(100 \mathrm{mg} / \mathrm{ml})$ in $1.15 \% \mathrm{KCl}$ buffer. Homogenates $(200 \mu \mathrm{l})$ were then added to a reaction mixture consisting of $1.5 \mathrm{ml}$ of $0.8 \%$ thiobarbituric acid, $200 \mu \mathrm{l}$ of $8.1 \% \mathrm{SDS}, 1.5 \mathrm{ml}$ of $20 \%$ acetic acid, $\mathrm{pH}$ 3.5, and $600 \mu \mathrm{l}$ of distilled $\mathrm{H}_{2} \mathrm{O}$, and the mixture was heated for 45 min at $90^{\circ} \mathrm{C}$. After cooling to room temperature, the samples were centrifuged at $10,000 \mathrm{~g}$ for $10 \mathrm{~min}$, and the absorbance of the supernatant at $532 \mathrm{~nm}$ was measured with 1,1,3,3-tetramethoxypropane as an external standard. The level of lipid peroxides was expressed as nanomoles of MDA per milligram of protein.

Detection of Apoptosis by TUNEL, Renal DNA Fragmentation, and Caspase-3/7 Activity Assays. Apoptosis was assessed by terminal deoxynucleotidyl transferase dUTP nick-end labeling staining (TUNEL), and the number of apoptotic cells, as defined by chromatin condensation or nuclear fragmentation (apoptotic bodies), was counted. Apoptosis was detected in the specimen using the ApopTag Plus peroxidase in situ apoptosis detection kit (Millipore Bioscience Research Reagents, Temecula, CA) according to the manufacturer's protocol. The morphometric examination was performed by two independent, blinded investigators. The number of apoptotic cells in each section was calculated by counting the number of TUNELpositive apoptotic cells in $10 \times 400$ fields per slide.

For caspase assay of tissue lysate, caspase-3/7 activity of the lysate was measured using Apo-One Homogenous caspase-3/7 assay kit (Promega, Madison, WI). An aliquot of caspase reagent was added to each well, mixed on a plate shaker for $1 \mathrm{~h}$ at room temperature with light protection, and the fluorescence was measured.

The DNA fragmentation assay is based on measuring the amount of mono- and oligonucleosomes in the cytoplasmic fraction of tissue extracts using a commercially available kit (Roche Diagnostics, Indianapolis, IN) according to manufacturer's instructions.

Renal PARP Activity. PARP activity was determined by assay kit according to manufacturer's instructions (Trevigen, Gaithersburg, MD).

Renal Nitrotyrosine Accumulation. Quantification of nitrotyrosine levels from kidney tissues were performed using the sandwich ELISA kit according to manufacturer's instructions (Hycult Biotechnology, Uden, The Netherlands).

Immunohistochemistry. Paraffin-embedded sections were cut, deparaffinized, and hydrated by soaking in $100 \%$ xylene and descending ethanol, followed by microwave antigen retrieval treatment. Next, sections were incubated in $0.3 \% \mathrm{H}_{2} \mathrm{O}_{2}$ in phosphatebuffered saline to block endogenous peroxidase activity. The sections were incubated with antinitrotyrosine (1:200 dilution) obtained from Cayman Chemical (Ann Arbor, MI) overnight at $4^{\circ} \mathrm{C}$ in a moist 
chamber. Biotinylated secondary antibodies and ATP-binding cassette reagent were applied. Color development was induced by incubation with a diaminobenzidine kit (Vector Laboratories, Burlingame, CA) for 3 to $5 \mathrm{~min}$, and specific staining was visualized by light microscopy.

Real-Time PCR Analyses. Total RNA was isolated from kidney homogenate using TRIzol LS reagents (Invitrogen, Carlsbad, CA) according to manufacturer's instructions. The isolated RNA was treated with RNase-free DNase (Ambion, Austin, TX) to remove traces of genomic DNA contamination. One microgram of total RNA was reverse-transcribed to cDNA using the SuperScript II (Invitrogen). The target gene expression was quantified with Power SYBER Green PCR Master Mix using an ABI 7500 real-time PCR instrument (Applied Biosystems, Foster City, CA). Each amplified sample in all wells was analyzed for homogeneity using dissociation curve analysis. After denaturation at $95^{\circ} \mathrm{C}$ for $2 \mathrm{~min}, 40$ cycles were performed at $95^{\circ} \mathrm{C}$ for $10 \mathrm{~s}$ and at $60^{\circ} \mathrm{C}$ for $30 \mathrm{~s}$. Relative quantification was calculated using the comparative $\mathrm{C}_{\mathrm{T}}$ method $\left(2^{-\Delta \Delta \mathrm{Ct}}\right.$ method: $\left.\Delta \Delta \mathrm{Ct}=\Delta \mathrm{C}_{\mathrm{t} \text { sample }}-\Delta \mathrm{C}_{\mathrm{t} \text { reference }}\right)$. Lower $\Delta \mathrm{C}_{\mathrm{T}}$ values and lower $\Delta \Delta \mathrm{C}_{\mathrm{T}}$ reflect a relatively higher amount of gene transcript. Statistical analyses were carried out for at least six to 15 replicate experimental samples in each set.

Primers used were as follows: TNF $\alpha, 5$ '-AAGCCTGTAGCCCACGTCGTA-3' and 5'-AGGTACAACCCATCGGCTGG-3'; IL-1 $\beta$, 5'-AAAAAAGCCTCGTGCTGTCG-3' and 5'-GTCGTTGCTTGGTTCTCCTTG-3'; iNOS, 5'-ATTCACAGCTCATCCGGTACG-3' and 5'GGATCTTGACCATCAGCTTGC-3'; NOX1, 5' -TCGAACGCTACAGAAGAAGCC-3' and 5'-TGGCAATCACTCCAGTAAGGC-3'; RENOX, 5'-TCATTTGGCTGTCCCTAAACG-3' and 5'-AAGGATGAGGCTGCAGTTGAG-3'; and actin, 5'-TGCACCACCAACTGCTTAG-3' and 5' GGATGCAGGGATGATGTTC-3'.

Statistical Analysis. Results are reported as mean \pm S.E.M. Statistical significance between two measurements was determined by the two-tailed unpaired Student's $t$ test (and among groups it was determined by analysis of variance followed by post hoc StudentNewman-Keuls) by using GraphPad Prism 4.3 software (GraphPad Software Inc., San Diego, CA). Probability values of $P<0.05$ were considered significant.

\section{Results}

CBD Attenuates the Cisplatin-Induced Renal Dysfunction in Mice. To investigate the effect of CBD on cisplatin (CP)-induced renal dysfunction, levels of BUN and creatinine were measured at $72 \mathrm{~h}$ after cisplatin administration in the serum of both CBD-treated and untreated mice. As shown in Figs. 1 and 2A, cisplatin administration resulted in severe renal injury, which was dose-dependently attenuated by CBD treatment ( $n=6$ /each group; $P<0.01$ ). CBD at $10 \mathrm{mg} / \mathrm{kg} /$ day i.p. was able to attenuate renal injury not only starting from $1.5 \mathrm{~h}$ before $\mathrm{CP}$ administration (Figs. 1 and 2A) but also when it was administered $12 \mathrm{~h}$ after the $\mathrm{CP}$ exposure $(n=6 ; P<0.01)$. CBD alone had no effects on BUN and creatinine levels compared with the vehicle-treated group $(n=5$; Fig. 2A).

CBD Attenuates the Cisplatin-Induced Tubular Necrosis and Apoptosis. Histological examination revealed necrosis, protein cast, vacuolation, and desquamation of epithelial cells in the renal tubules of the cisplatin-treated control group. Treatment with CBD (10 mg/kg/day i.p. starting from $1.5 \mathrm{~h}$ before the $\mathrm{CP}$ exposure) dramatically improved the cisplatin-induced renal tubular damage (Fig. 2B; $n=6 ; P<0.01$ ). Apoptosis of renal tubular epithelial cells was evaluated by TUNEL, and caspase-3/7 activity, and DNA fragmentation assays. As shown in Figs. $3 \mathrm{~A}$ and $4 \mathrm{~A}$, the

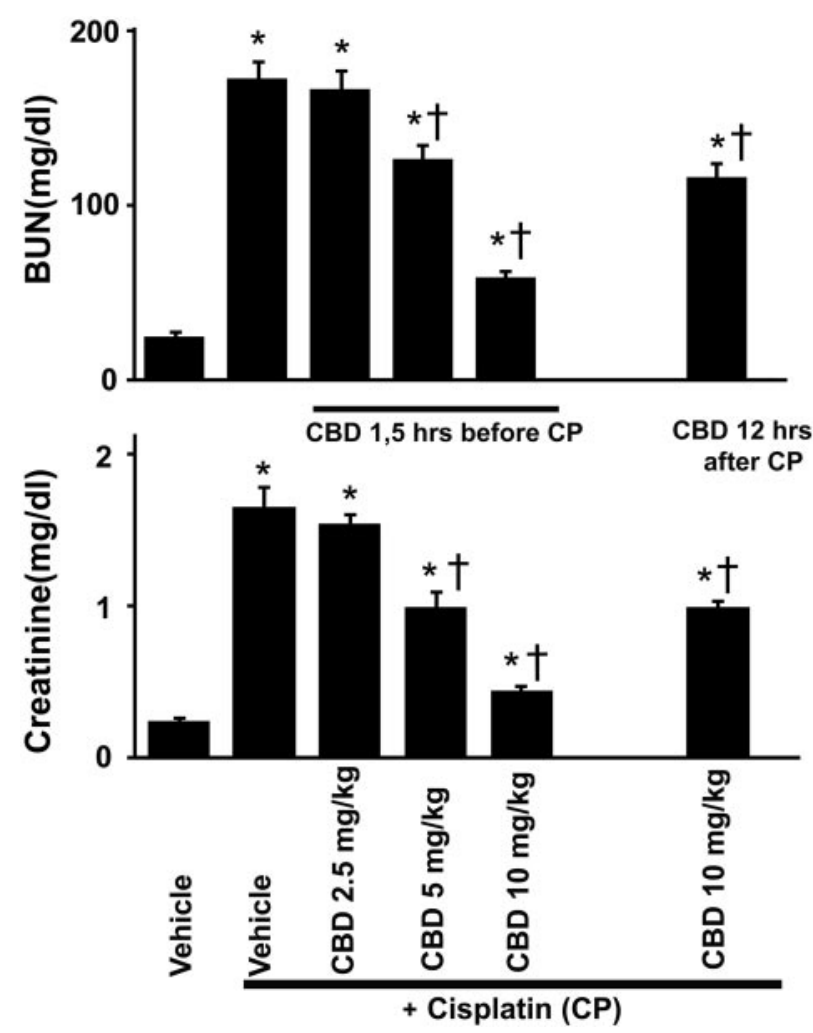

Fig. 1. Cannabidiol dose-dependently attenuates the cisplatin-induced renal dysfunction. CP induced profound renal dysfunction $72 \mathrm{~h}$ after the administration to mice evidenced by increased serum levels of BUN and creatinine, which were dose-dependently attenuated by CBD treatment. $\mathrm{CBD}(10 \mathrm{mg} / \mathrm{kg} /$ day i.p.), even given $12 \mathrm{~h}$ after the CP exposure, was able to attenuate the renal dysfunction. Results are mean \pm S.E.M. of six experiments in each group. $*, P<0.05$ versus vehicle; $\dagger, P<0.05$ versus cisplatin.

caspase-3/7 activity and DNA fragmentation in kidney homogenates were markedly increased after cisplatin administration and significantly attenuated by CBD treatment $(n=$ 6; $P<0.01$ ). TUNEL-positive apoptotic cell numbers were also increased in cisplatin-treated mice and attenuated by CBD treatment (Fig. 3B; $n=6 ; P<0.01$ ). CBD also attenuated the cisplatin-induced increased PARP activity in the kidneys (Fig. 4B; $n=6 ; P<0.01$ ). CBD alone had no effects on the above-mentioned variables $(n=5)$.

CBD Attenuates the Cisplatin-Induced Inflammation. Cisplatin markedly increased the mRNA expression of TNF- $\alpha$ and IL1 $\beta$, indicating enhanced inflammatory response, which was attenuated by CBD treatment (Fig. 4, C and $\mathrm{D} ; n=6 ; P<0.01)$. CBD alone had no effects on the inflammatory markers $(n=5)$.

CBD Attenuates the Cisplatin-Induced Increased ROS Formation and Enhanced Expression of Superoxide-Generating Enzymes RENOX (NOX4) and NOX1. The mRNAs for subunits of RENOX (NOX4) and phagocyte NADPH oxidase (NOX1) were increased in the kidneys of cisplatin-treated mice. Such increases were attenuated by CBD treatment (Fig. 5, A and B; $n=6 ; P<0.01$ and $P<$ 0.05 , respectively). CBD alone had no effects on the mRNA expression of NOX4 and NOX1 $(n=5)$.

Cisplatin induced marked elevation of MDA levels, one of the end products of lipid peroxidation and an indicator of ROS production, which was attenuated by CBD treatment 

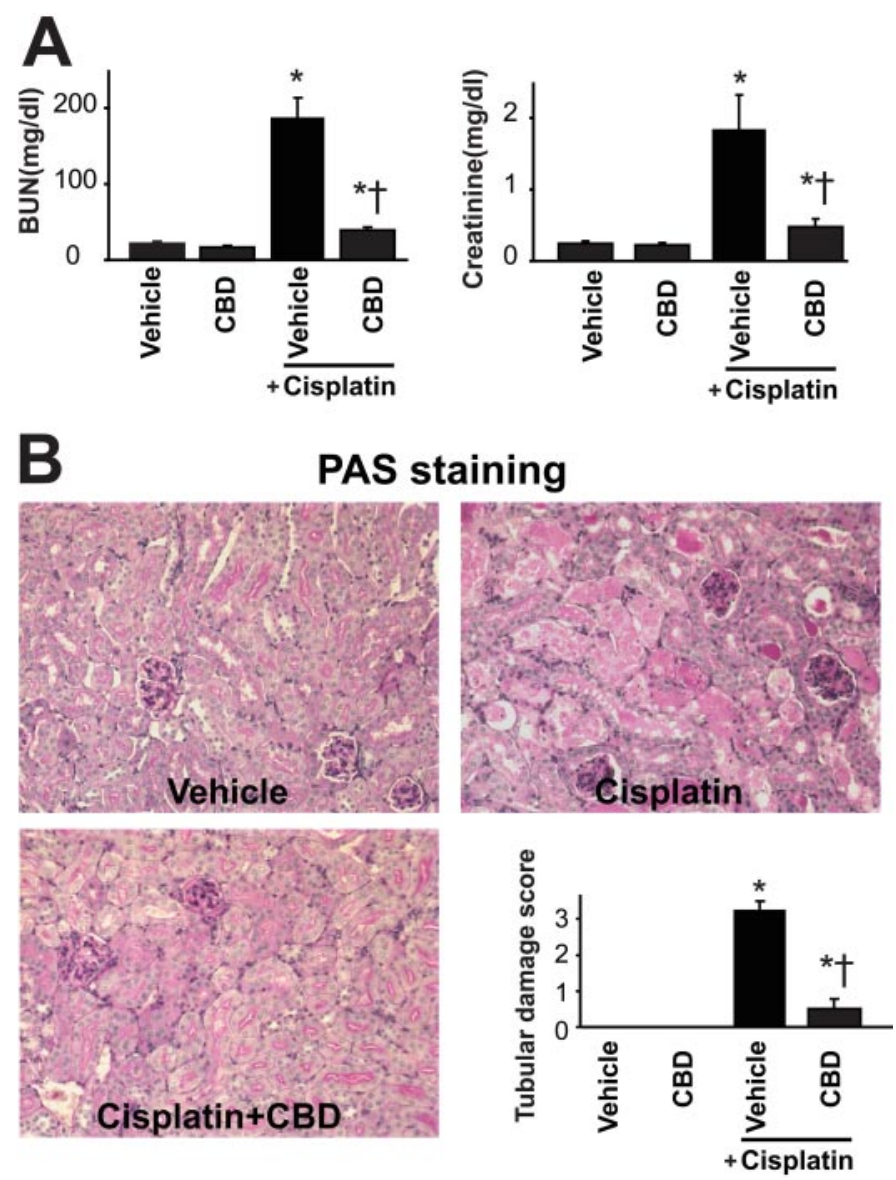

Fig. 2. Cannabidiol attenuates the cisplatin-induced renal dysfunction and histopathological damage. Cisplatin induced profound renal dysfunction and injury $72 \mathrm{~h}$ after the administration to mice evidenced by increased serum levels of BUN and creatinine (A) and histopathological damage evaluated by PAS staining (B), which were attenuated by CBD treatment $(10 \mathrm{mg} / \mathrm{kg} /$ day i.p. starting from $1.5 \mathrm{~h}$ before $\mathrm{CP}$ exposure). Results are mean \pm S.E.M. of five to six experiments in each group. $*, P<$ 0.05 versus vehicle; $\dagger, P<0.05$ versus cisplatin.

(Fig. $5 \mathrm{C} ; n=6 ; P<0.01$ ). CBD alone had no effects on MDA $(n=5)$.

CBD Attenuates the Cisplatin-Induced Increased iNOS mRNA and Protein Expression. Cisplatin markedly increased both the mRNA and protein expression of iNOS, which were attenuated by CBD treatment (Fig. 6, A and $\mathrm{B} ; n=6 ; P<0.01)$. CBD alone had no effects on the iNOS expression $(n=5)$.

CBD Attenuates the Cisplatin-Induced Increased 3-Nitrotyrosine Formation. Cisplatin markedly increases the NT formation as revealed by immunohistochemistry staining and quantitative ELISA from kidney homogenates, which were attenuated by CBD treatment (Fig. 7, A and B; $n=6 ; P<0.01)$. CBD alone had no effects on NT generation $(n=6)$.

\section{Discussion}

In the present study, we have assessed the effects of CBD, a nonpsychoactive component of marijuana, on cisplatininduced renal oxidative/nitrosative stress, cell death, and consequent kidney dysfunction. We demonstrate that CBD attenuates cisplatin-induced increased expression of superoxide-generating enzymes RENOX (NOX4) and phagocyte
NOX1, ROS generation, iNOS expression, nitrotyrosine formation, inflammation, and apoptosis/necrosis in the kidney of mice, associated with marked improvement of compromised renal function.

CBD has been demonstrated to exert antioxidant and antiinflammatory effects in numerous preclinical models of inflammatory and degenerative diseases known to be associated with increased ROS and reactive nitrogen species generation, as well as in in vitro systems, independently from classical $\mathrm{CB}_{1}$ and $\mathrm{CB}_{2}$ receptors (Hampson et al., 1998; Chen and Buck, 2000; Malfait et al., 2000; Costa et al., 2004; Hayakawa et al., 2004; Iuvone et al., 2004; Sacerdote et al., 2005; El-Remessy et al., 2006; Esposito et al., 2006; Weiss et al., 2006, 2008; Durst et al., 2007; Rajesh et al., 2007). CBD is devoid of psychoactive effects because of a low affinity for the central nervous system $\mathrm{CB}_{1}$ receptors (Thomas et al., 1998; Pacher et al., 2006) and is well tolerated when chronically administered to humans (Cunha et al., 1980; Consroe et al., 1991). CBD has been approved for the treatment of inflammation, pain, and spasticity associated with multiple sclerosis in humans since 2005 (Barnes, 2006; Pacher et al., 2006; Mechoulam et al., 2007).

Cisplatin is one of the most potent chemotherapy agents available to treat various malignancies. However, the major
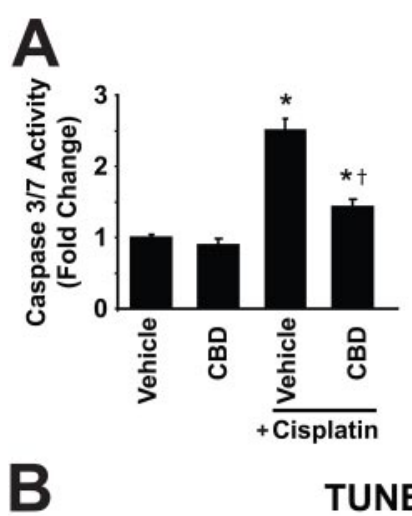

TUNEL staining
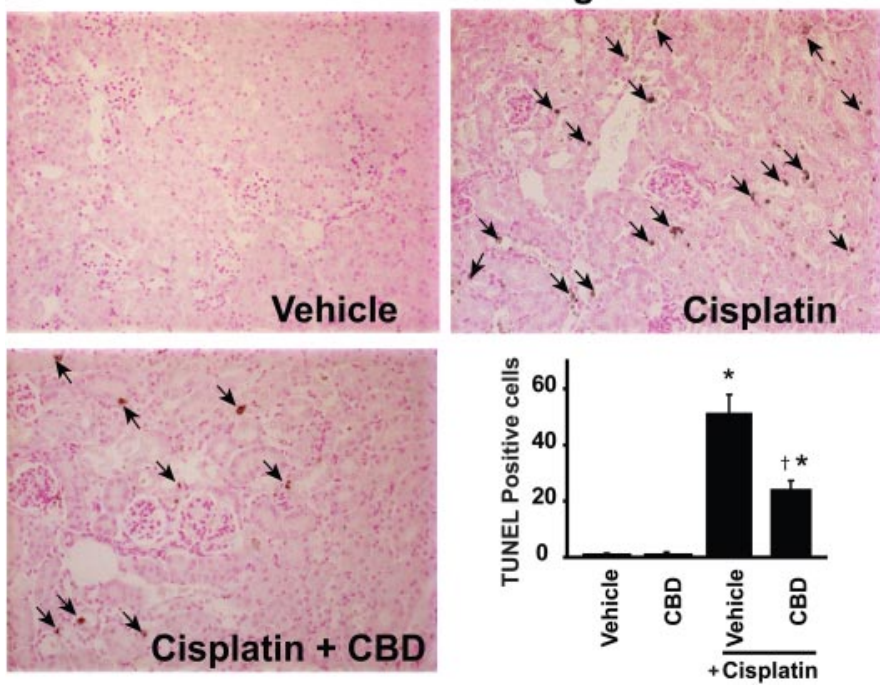

Fig. 3. Cannabidiol attenuates the cisplatin-induced renal caspase- $3 / 7$ (A) activity and TUNEL staining (B). Cisplatin induced marked increases in caspase-3/7 activity (A) and TUNEL staining (B) in the kidneys of treated mice $72 \mathrm{~h}$ after the administration to mice, which were attenuated by CBD treatment $(10 \mathrm{mg} / \mathrm{kg} /$ day i.p. starting from $1.5 \mathrm{~h}$ before $\mathrm{CP}$ exposure). Results are mean \pm S.E.M. of five to six experiments in each group. *, $P<0.05$ versus vehicle; $\dagger, P<0.05$ versus cisplatin. 
limitation of cisplatin chemotherapy is the dose-dependent nephrotoxicity. Unfortunately, efficient pharmacotherapies to decrease this devastating complication of chemotherapy are not available.

Increased oxidative (Matsushima et al., 1998; Davis et al., 2001) and nitrosative (Chirino et al., 2004, 2008) stress and inflammation (Yamate et al., 2002; Faubel et al., 2007) and the activation of downstream effector cell death pathways (e.g., PARP; Racz et al., 2002) play a critical role in the pathophysiology of cisplatin-induced cell death culminating in renal dysfunction. The cellular sources of increased superoxide production are multiple and may include NADH/ NADPH and xanthine oxidases and the mitochondrial respiratory chain, to name a few. In our study, we found marked overexpression of NOX4 [RENOX; NAD $(\mathrm{P}) \mathrm{H}$ oxidase isoform considered to be the main source of ROS in the kidney; Geiszt et al., 2000] and to a lesser extent phagocyte $\mathrm{NAD}(\mathrm{P}) \mathrm{H}$ oxidase (NOX1), accompanied by marked increase in ROS generation, in kidneys of cisplatin-treated mice. Cisplatin also induced marked up-regulation of TNF- $\alpha$ and IL- $1 \beta$ mRNA in the kidney, consistent with the important role of inflammatory component, particularly cytokine TNF- $\alpha$ (Ramesh and Reeves, 2002; Zhang et al., 2007), in the drug-induced nephrotoxicity. Cisplatin-induced superoxide generation might also favor increased expression of iNOS through the activation of nuclear factor- $\kappa \mathrm{B}$, which increases the generation of NO. Indeed, we found marked iNOS overexpression in the kidneys of cisplatin-treated mice. The pathophysiological role
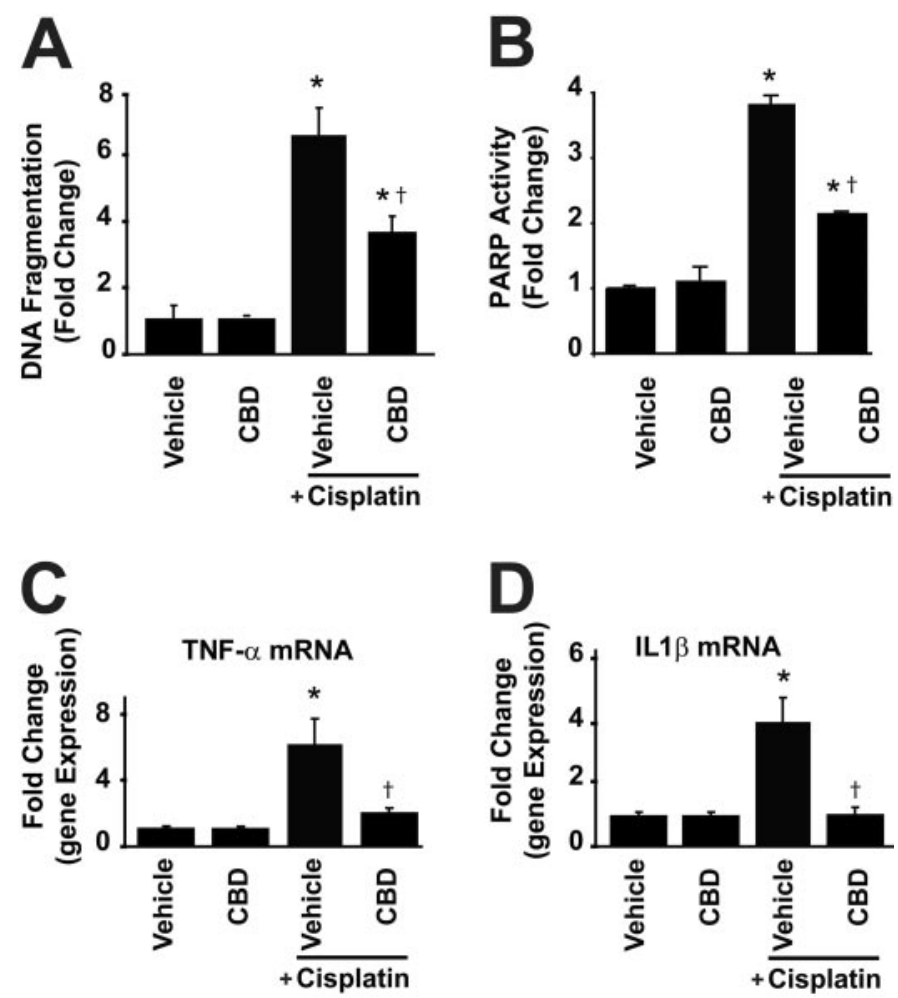

Fig. 4. Cannabidiol attenuates the cisplatin-induced renal DNA fragmentation (A), PARP activity (B), and inflammation (C and D). Cisplatin induced marked increases in DNA fragmentation (A), PARP activity (B), and mRNA expression of TNF- $\alpha$ (C) and IL-1 $\beta$ (D) in the kidneys $72 \mathrm{~h}$ after the administration to mice, which were attenuated by CBD treatment (10 mg/kg/day i.p. starting from $1.5 \mathrm{~h}$ before CP exposure). Results are mean \pm S.E.M. of five to six experiments in each group. $*, P<0.05$ versus vehicle; $\uparrow, P<0.05$ versus cisplatin.
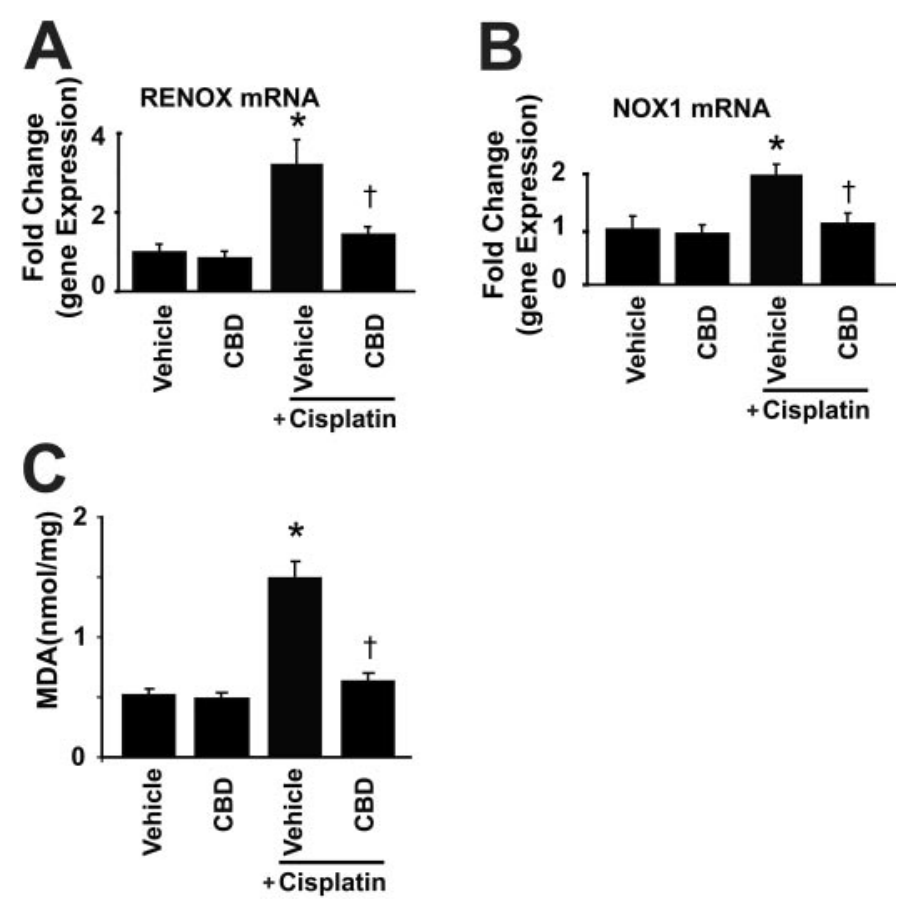

Fig. 5. Cannabidiol attenuates the cisplatin-induced renal overexpression of superoxide generating enzymes NOX4 (RENOX) and NOX1 (A and B) and MDA formation. Cisplatin induced marked increases in mRNA expression of NOX4 and NOX1 (A and B) and increased lipid peroxidation (C) in the kidneys $72 \mathrm{~h}$ after the administration to mice, which were attenuated by CBD (10 mg/kg/day i.p. starting from $1.5 \mathrm{~h}$ before $\mathrm{CP}$ exposure) treatment. Results are mean \pm S.E.M. of five to six experiments in each group. *, $P<0.05$ versus vehicle; $\dagger, P<0.05$ versus cisplatin.

of iNOS-derived NO in this model is also supported by recent findings demonstrating that selective iNOS inhibition reduces renal damage induced by cisplatin (Chirino et al., 2008). Superoxide anion interacts with NO, forming the potent cytotoxin peroxynitrite, that attacks various biomolecules, leading to organ dysfunction via multiple mechanisms (Pacher et al., 2007). Indeed, the pathogenetic role of nitrosative stress and peroxynitrite and downstream mechanisms such as PARP have recently been implicated in the development of cisplatin-induced cell death and consequent nephropathy (Racz et al., 2002; Chirino et al., 2004, 2008).

CBD treatment largely attenuated the cisplatin-induced increased expression of ROS-generating enzymes NOX4 and NOX1 and consequent renal oxidative stress. In addition, CBD also decreased the cisplatin-induced inflammatory response (TNF- $\alpha$ and IL-1 $\beta$ levels), iNOS overexpression, and nitrotyrosine formation (the marker of peroxynitrite generation and more broadly nitrosative stress) (Pacher et al., 2007) in the kidneys, and consequent cell death (both apoptotic and necrotic) and renal dysfunction.

Although the exact mechanism of the anticancer activity of the cisplatin is not completely understood, it is widely held that it binds to DNA, leading to the formation of inter- and intrastrand cross-links, resulting in defective DNA templates and arrest of DNA synthesis and replication, particularly in rapidly dividing cancer cells (Wang and Lippard, 2005; Pabla and Dong, 2008). Although numerous other signaling mechanisms have also been implicated in the antitumor activity of the compound, the oxidative/nitrosative stress does not seem to play a major role (Wang and Lippard, 2005). This is also 
analogous to other potent chemotherapeutic agent doxorubicin, the major limitation of which is the cardiotoxicity, which also involves increased oxidative/nitrosative stress (Pacher et al., 2003, 2007). Potent antioxidant approaches, which decrease the cardiotoxicity of doxorubicin, do not interfere with its antitumor activity (Pacher et al., 2003). In fact, the clinically approved agent for prevention of doxorubicin-induced heart failure, the iron-chelating agent dexrazoxane, is a potent antioxidant. Therefore, it is not likely that the antioxidant effect of the CBD would interfere with its chemotherapeutic efficacy. In addition, CBD by itself and its derivative Hu-331 (Kogan et al., 2006) have also been demonstrated to exert various antitumor properties (e.g., inhibition of growth and migration of various cancer cell lines, inhibition of angiogenesis, and attenuation of the growth of xenograft tumors in mice; Vaccani et al., 2005; Kogan et al., 2006; Ligresti et al., 2006; McAllister et al., 2007), which rather predict additive and/or synergistic anticancer effect(s) of $\mathrm{CBD}$ in combination with various chemotherapeutic agents, undoubtedly deserving further exploration in upcoming studies.

In summary, our results suggest that the nonpsychoactive cannabinoid $\mathrm{CBD}$ may be of significant therapeutic benefits against the renal complications of cisplatin chemotherapy by attenuating oxidative/nitrosative stress and cell death. This is particularly encouraging in light of the excellent safety and tolerability profile of CBD in humans and reported antican-

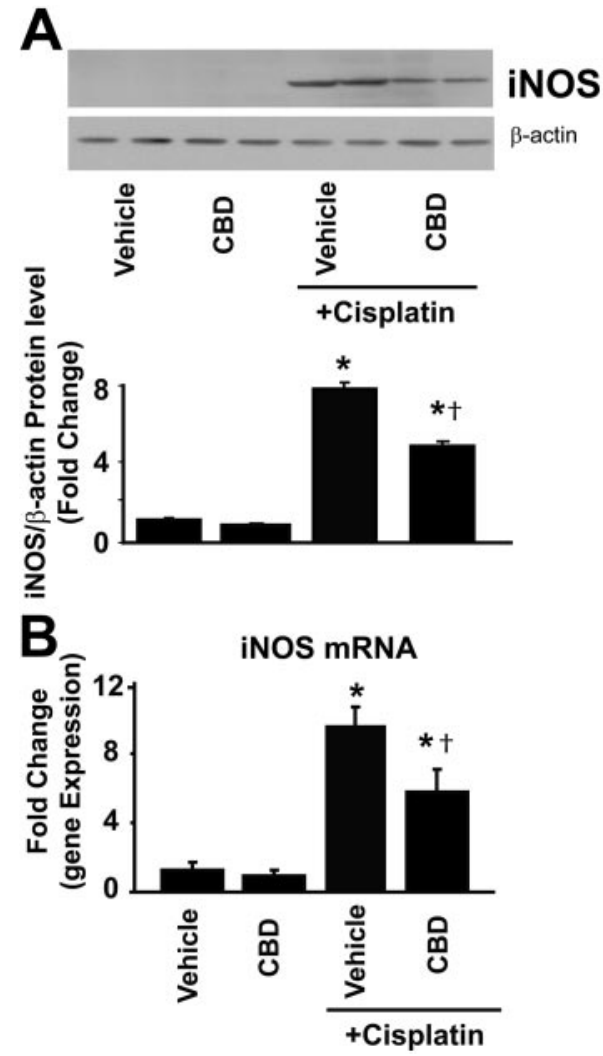

Fig. 6. Cannabidiol attenuates the cisplatin-induced renal overexpression of iNOS. Cisplatin induced marked increases in protein (A) and mRNA (B) expression of iNOS in the kidneys $72 \mathrm{~h}$ after the administration to mice, which were attenuated by CBD treatment $(10 \mathrm{mg} / \mathrm{kg} /$ day i.p. starting from $1.5 \mathrm{~h}$ before $\mathrm{CP}$ exposure). Results are mean \pm S.E.M. of five to six experiments in each group. $*, P<0.05$ versus vehicle; $\dagger, P<$ 0.05 versus cisplatin.

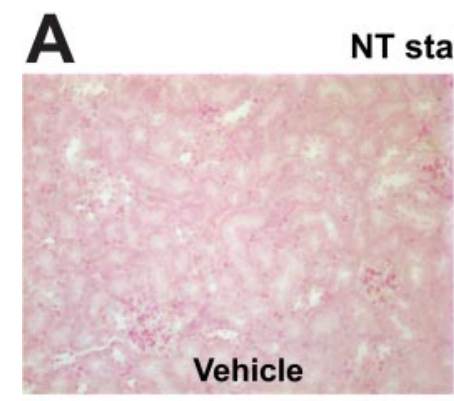

NT staining
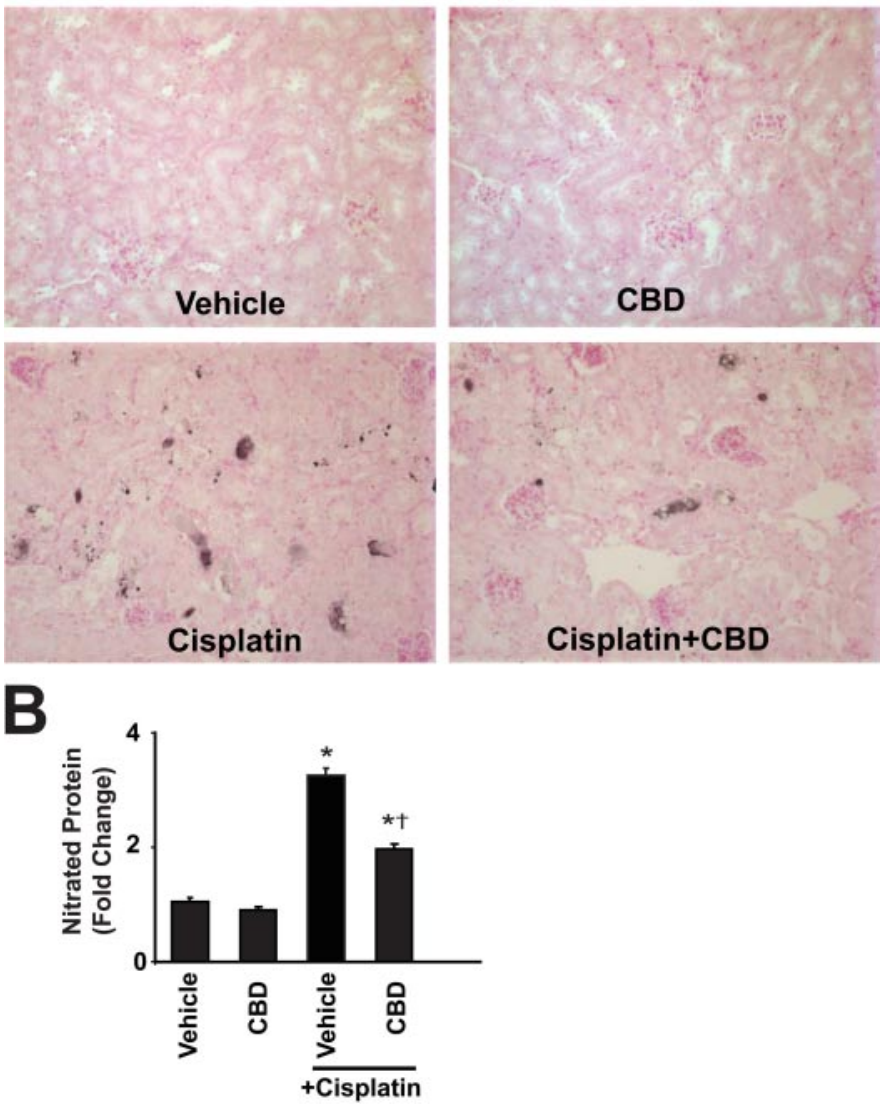

Fig. 7. Cannabidiol attenuates the cisplatin-induced renal NT formation Cisplatin induced marked increases in NT staining in the kidneys (A, representative sections) and in nitrated proteins evaluated by quantitative ELISA (B) in the kidneys $72 \mathrm{~h}$ after the administration to mice, which were attenuated by CBD $(10 \mathrm{mg} / \mathrm{kg} /$ day i.p. starting from $1.5 \mathrm{~h}$ before $\mathrm{CP}$ exposure) treatment. Results are mean \pm S.E.M. of five to six experiments in each group. *, $P<0.05$ versus vehicle; $\dagger, P<0.05$ versus cisplatin.

cer and antiangiogenic effect of the compound and its derivatives (Mechoulam et al., 2007).

\section{Acknowledgments}

P.P. dedicates this study to his beloved mother Iren Bolfert, who died from the complications of chemotherapy. We are indebted to Prof. Raphael Mechoulam for providing cannabidiol and for valuable comments on the manuscript.

\section{References}

Barnes MP (2006) Sativex: clinical efficacy and tolerability in the treatment of symptoms of multiple sclerosis and neuropathic pain. Expert Opin Pharmacother 7:607-615

Chen Y and Buck J (2000) Cannabinoids protect cells from oxidative cell death: a receptor-independent mechanism. $J$ Pharmacol Exp Ther 293:807-812.

Chirino YI, Hernández-Pando R, and Pedraza-Chaverrí J (2004) Peroxynitrite decomposition catalyst ameliorates renal damage and protein nitration in cisplatininduced nephrotoxicity in rats. BMC Pharmacol 4:20.

Chirino YI, Trujillo J, Sánchez-González DJ, Martínez-Martínez CM, Cruz C, Bobadilla NA, and Pedraza-Chaverri J (2008) Selective iNOS inhibition reduces renal damage induced by cisplatin. Toxicol Lett 176:48-57.

Consroe P, Laguna J, Allender J, Snider S, Stern L, Sandyk R, Kennedy K, and Schram K (1991) Controlled clinical trial of cannabidiol in Huntington's disease. Pharmacol Biochem Behav 40:701-708.

Costa B, Colleoni M, Conti S, Parolaro D, Franke C, Trovato AE, and Giagnoni G (2004) Oral anti-inflammatory activity of cannabidiol, a non-psychoactive constituent of cannabis, in acute carrageenan-induced inflammation in the rat paw. Naunyn Schmiedebergs Arch Pharmacol 369:294-299.

Cunha JM, Carlini EA, Pereira AE, Ramos OL, Pimentel C, Gagliardi R, Sanvito WL, Lander N, and Mechoulam R (1980) Chronic administration of cannabidiol to healthy volunteers and epileptic patients. Pharmacology 21:175-185. 
Davis CA, Nick HS, and Agarwal A (2001) Manganese superoxide dismutase attenuates cisplatin-induced renal injury: importance of superoxide. J Am Soc Nephrol 12:2683-2690.

Durst R, Danenberg H, Gallily R, Mechoulam R, Meir K, Grad E, Beeri R, Pugatsch T, Tarsish E, and Lotan C (2007) Cannabidiol, a nonpsychoactive Cannabis constituent, protects against myocardial ischemic reperfusion injury. Am J Physiol Heart Circ Physiol 293:H3602-H3607.

El-Remessy AB, Al-Shabrawey M, Khalifa Y, Tsai NT, Caldwell RB, and Liou GI (2006) Neuroprotective and blood-retinal barrier-preserving effects of cannabidiol in experimental diabetes. Am J Pathol 168:235-244.

Esposito G, De Filippis D, Maiuri MC, De Stefano D, Carnuccio R, and Iuvone T (2006) Cannabidiol inhibits inducible nitric oxide synthase protein expression and nitric oxide production in beta-amyloid stimulated PC12 neurons through p38 MAP kinase and NF-kappaB involvement. Neurosci Lett 399:91-95.

Faubel S, Lewis EC, Reznikov L, Ljubanovic D, Hoke TS, Somerset H, Oh DJ, Lu L, Klein CL, Dinarello CA, et al. (2007) Cisplatin-induced acute renal failure is associated with an increase in the cytokines interleukin (IL)-1beta, IL-18, IL-6, and neutrophil infiltration in the kidney. $J$ Pharmacol Exp Ther 322:8-15.

Gaoni Y and Mechoulam R (1971) The isolation and structure of delta-1 tetrahydrocannabinol and other neutral cannabinoids from hashish. J Am Chem Soc 93:217-224.

Geiszt M, Kopp JB, Várnai P, and Leto TL (2000) Identification of renox, an NAD(P)H oxidase in kidney. Proc Natl Acad Sci U S A 97:8010-8014.

Hampson AJ, Grimaldi M, Axelrod J, and Wink D (1998) Cannabidiol and (-) $\Delta 9$ tetrahydrocannabinol are neuroprotective antioxidants. Proc Natl Acad Sci U S A 95: $8268-8273$.

Hayakawa K, Mishima K, Abe K, Hasebe N, Takamatsu F, Yasuda H, Ikeda T, Inui K, Egashira N, Iwasaki K, et al. (2004) Cannabidiol prevents infarction via the non-CB1 cannabinoid receptor mechanism. Neuroreport 15:2381-2385.

Iuvone T, Esposito G, Esposito R, Santamaria R, Di Rosa M, and Izzo AA (2004) Neuroprotective effect of cannabidiol, a non-psychoactive component from Cannabis sativa, on beta-amyloid-induced toxicity in PC12 cells. J Neurochem 89:134141.

Kogan NM, Blázquez C, Alvarez L, Gallily R, Schlesinger M, Guzmán M, and Mechoulam R (2006) A cannabinoid quinone inhibits angiogenesis by targeting vascular endothelial cells. Mol Pharmacol 70:51-59.

Ligresti A, Moriello AS, Starowicz K, Matias I, Pisanti S, De Petrocellis L, Laezza C, Portella G, Bifulco M, and Di Marzo V (2006) Antitumor activity of plant cannabinoids with emphasis on the effect of cannabidiol on human breast carcinoma. $J$ Pharmacol Exp Ther 318:1375-1387.

Malfait AM, Gallily R, Sumariwalla PF, Malik AS, Andreakos E, Mechoulam R, and Feldmann M (2000) The nonpsychoactive cannabis constituent cannabidiol is an oral anti-arthritic therapeutic in murine collagen-induced arthritis. Proc Natl Acad Sci U S A 97:9561-9566.

Matsushima H, Yonemura K, Ohishi K, and Hishida A (1998) The role of oxygen free radicals in cisplatin-induced acute renal failure in rats. J Lab Clin Med 131:518 526.

McAllister SD, Christian RT, Horowitz MP, Garcia A, and Desprez PY (2007) Cannabidiol as a novel inhibitor of Id-1 gene expression in aggressive breast cancer cells. Mol Cancer Ther 6:2921-2927.

Mechoulam R, Peters M, Murillo-Rodriguez E, and Hanus LO (2007) Cannabidiolrecent advances. Chem Biodivers 4:1678-1692.

Pabla N and Dong Z (2008) Cisplatin nephrotoxicity: mechanisms and renoprotective strategies. Kidney Int 73:994-1007.
Pacher P, Bátkai S, and Kunos G (2006) The endocannabinoid system as an emerging target of pharmacotherapy. Pharmacol Rev 58:389-462.

Pacher P, Beckman JS, and Liaudet L (2007) Nitric oxide and peroxynitrite in health and disease. Physiol Rev 87:315-424.

Pacher P, Liaudet L, Bai P, Mabley JG, Kaminski PM, Virág L, Deb A, Szabó E, Ungvári Z, Wolin MS, et al. (2003) Potent metalloporphyrin peroxynitrite decomposition catalyst protects against the development of doxorubicin-induced cardiac dysfunction. Circulation 107:896-904

Racz I, Tory K, Gallyas F Jr, Berente Z, Osz E, Jaszlits L, Bernath S, Sumegi B, Rabloczky G, and Literati-Nagy P (2002) BGP-15-a novel poly(ADP-ribose) polymerase inhibitor-protects against nephrotoxicity of cisplatin without compromising its antitumor activity. Biochem Pharmacol 63:1099-1111.

Rajesh M, Mukhopadhyay P, Bátkai S, Haskó G, Liaudet L, Drel VR, Obrosova IG and Pacher P (2007) Cannabidiol attenuates high glucose-induced endothelial cel inflammatory response and barrier disruption. Am J Physiol Heart Circ Physiol 293:H610-H619.

Ramesh G and Reeves WB (2002) TNF-alpha mediates chemokine and cytokine expression and renal injury in cisplatin nephrotoxicity. J Clin Invest 110:835-842. Ries F and Klastersky J (1986) Nephrotoxicity induced by cancer chemotherapy with special emphasis on cisplatin toxicity. Am J Kidney Dis 8:368-379.

Sacerdote P, Martucci C, Vaccani A, Bariselli F, Panerai AE, Colombo A, Parolaro D, and Massi P (2005) The nonpsychoactive component of marijuana cannabidiol modulates chemotaxis and IL-10 and IL-12 production of murine macrophages both in vivo and in vitro. J Neuroimmunol 159:97-105.

Sugiyama S, Hayakawa M, Kato T, Hanaki Y, Shimizu K, and Ozawa T (1989) Adverse effects of anti-tumor drug, cisplatin, on rat kidney mitochondria: disturbances in glutathione peroxidase activity. Biochem Biophys Res Commun 159: 1121-1127.

Thomas BF, Gilliam AF, Burch DF, Roche MJ, and Seltzman HH (1998) Comparative receptor binding analyses of cannabinoid agonists and antagonists. $J$ Phar macol Exp Ther 285:285-292.

Vaccani A, Massi P, Colombo A, Rubino T, and Parolaro D (2005) Cannabidiol inhibits human glioma cell migration through a cannabinoid receptor-independent mechanism. Br J Pharmacol 144:1032-1036.

Wang D and Lippard SJ (2005) Cellular processing of platinum anticancer drugs Nat Rev Drug Discov 4:307-320.

Weiss L, Zeira M, Reich S, Har-Noy M, Mechoulam R, Slavin S, and Gallily R (2006 Cannabidiol lowers incidence of diabetes in non-obese diabetic mice. Autoimmunity 39:143-151.

Weiss L, Zeira M, Reich S, Slavin S, Raz I, Mechoulam R, and Gallily R (2008) Cannabidiol arrests onset of autoimmune diabetes in NOD mice. Neuropharmacology 54:244-249.

Yamate J, Sato K, Ide M, Nakanishi M, Kuwamura M, Sakuma S, and Nakatsuji S (2002) Participation of different macrophage populations and myofibroblastic cells in chronically developed renal interstitial fibrosis after cisplatin-induced rena injury in rats. Vet Pathol 39:322-333.

Zhang B, Ramesh G, Norbury CC, and Reeves WB (2007) Cisplatin-induced nephrotoxicity is mediated by tumor necrosis factor-alpha produced by renal parenchymal cells. Kidney Int 72:37-44.

Address correspondence to: Dr. Pál Pacher, Section on Oxidative Stress Tissue Injury, Laboratory of Physiological Studies, National Institutes of Health, National Institute on Alcohol Abuse and Alcoholism, 5625 Fishers Lane, MSC-9413, Bethesda, MD 20892-9413. E-mail: pacher@mail.nih.gov 